\title{
Distribution of First Row Transition Elements in Eclogites
}

\author{
N.M. HARMON ${ }^{1}$, A.M. CRUZ-URIBE ${ }^{1}$, J.W ALTERS ${ }^{1,2}$ \\ ${ }^{1}$ School of Earth and Climate Sciences, University of \\ Maine, Orono, ME 04469 (*correspondence: \\ natalie.harmon1@maine.edu, \\ alicia.cruzuribe@maine.edu,jesse.walters@maine.edu) \\ ${ }^{2}$ Goethe Universität, Frankfurt, Germany
}

Here we present concentrations of first row transition elements (FRTEs) in rutile, garnet, and omphacite in oceanic eclogites from the Guatemala Suture Zone, Czech Republic, and Southern Alps (Alpe Arami). Data were collected by LA-ICP-MS using an ESI NWR193 ${ }^{\text {UC }}$ laser ablation system coupled to an Agilent 8900 ICP-MS/MS. Rutile was ablated using a $12 \mu \mathrm{m}$ spot size at $3 \mathrm{~J} / \mathrm{cm}^{2}$ and 8 $\mathrm{Hz}$. Omphacite and garnet were ablated using a $17 \mu \mathrm{m}$ spot size at $3 \mathrm{~J} / \mathrm{cm}^{2}$ and $5 \mathrm{~Hz}$. Trace element concentrations in garnet and omphacite were determined relative to NIST SRM612, and relative to R10 for rutile. NIST SRM610, GSD-1G, GSE-1G, and R19 were analyzed as quality control materials.

Elements such as $\mathrm{V}$ and $\mathrm{Cr}$ are prefferentially partitioned into rutile over the silicates, whereas Sc, Co, Zn, and $\mathrm{Ge}$ are predominently found in omphacite and garnet. Scandium, Co, and Ga were below detection limit in rutile, and $\mathrm{Ni}$ and $\mathrm{Ge}$ were only measurable in omphacite and garnet, respectively. Scandium is more compatable in garnet than omphacite. Zinc and $\mathrm{Ga}$ are more compatible in omphacite than garnet. Omphacite/garnet partition coefficients for Co are close to 1 .

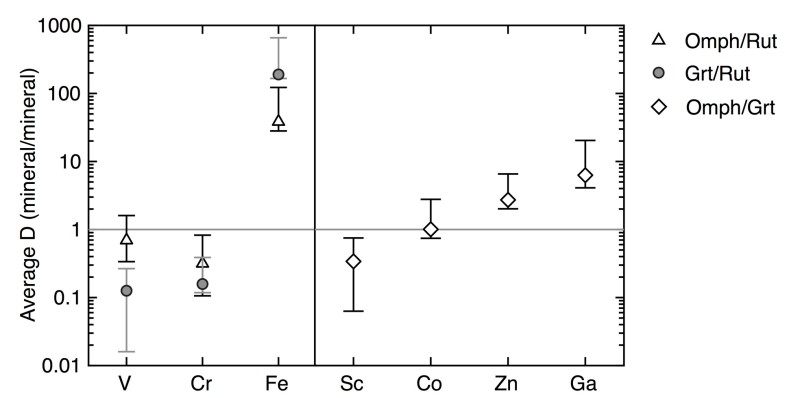

Figure 1. Average mineral-mineral partition coefficients for FRTEs in oceanic eclogites. Error bars indicate minimum and maximum for each of the three samples; symbol represents average of the three samples. Each sample is the average of 15-30 spot analyses. 